\title{
IDIOPATHIC INTRACRANIAL HYPERTENSION IN A WOMAN WITH SCHIZOPHRENIA
}

\author{
Alexandra J. Tzoukeva, Nadezhda S. Deleva, Ara G. Kaprelyan, Ivan N. Dimitrov \\ First Clinic of Neurology \\ University “Sveta Marina” Hospital, Varna, Bulgaria
}

\begin{abstract}
:
Idiopathic intracranial hypertension (IIH) or benign intracranial hypertension is a neurological syndrome characterized by elevated intracranial pressure. This uncommon disorder occurs primarily in obese women aged 10 to 50 years, sometimes in association with endocrine and metabolic dysfunction, with systemic diseases or when treated with multiple medications.

We describe a case of IIH in a 43 -year-old woman with schizophrenia treated with risperidone, demonstrating a typical clinical picture of benign intracranial hypertension. For the 5 years of treatment with risperidone she put on $35 \mathrm{~kg}$ in total (BMI> 35); for the last 2-3 months she began to complain of visual obscurations, nausea with vomiting. Ophthalmoscopy revealed bilateral asymmetric papilledema $(\mathrm{OD}>\mathrm{OS})$. Magnetic resonance imaging was normal, intracranial pressure was elevated IIH was diagnosed. Risperidone was discontinued and replaced with Seroquel 200 mg daily. Treatment with furosemide and mannitol $10 \%$ was initiated. Papilledema resolved completely over the next 2 months. The patient was followed-up for four years after risperidone withdrawal. Weight loss of $28 \mathrm{~kg}$ was noted for four years. There were no relapses of headache, nausea, visual obscuration. Ophthalmologic examination revealed no papilledema.
\end{abstract}

We suggest that prolonged use of antipsychotics, such as risperidone, should require proper surveillance for possible development of IIH and routine ophthalmologic examinations should be performed.

Key words: Idiopathic intracranial hypertension, Benign intracranial hypertension, Risperidone, Weight gain, Schizophrenia.

\section{BACKGROUND:}

Idiopathic intracranial hypertension (IIH) or benign intracranial hypertension is a neurological syndrome characterized by elevated intracranial pressure. Though its origin seems to be dependent on multiple factors, most cases remain idiopathic $(1,3,5,7,10,15,17)$. This uncommon disorder occurs primarily in obese women aged 10 to 50 years, sometimes in association with endocrine and metabolic dysfunction, with systemic diseases or when treated with multiple medications $(2,7,8,14)$. The association between some exogenous substances, such as drugs, and the development of IIH is well documented. Tetracycline antibiotics (tetracycline, monocycline, doxycycline), vitamin A and other retinoids, as well as corticosteroid withdrawal, are considered to be the most frequent causes $(6,9)$. For others however a causal relationship is uncertain: amiodarone, growth hormone, levodopa, cyclosporine, oral contraceptives, oxytocin, indomethacin, lithium carbonate $(7,14,16,17)$. Only few cases have been described about the influence of these drugs on the development of IIH, and on the other hand, follow-up after their withdrawal is not always long enough. Moreover, drug withdrawal is not reported to be curative only in all patients. It is therefore very important and useful to examine closely and describe such cases.

The clinical features of IIH are generally those of increased intracranial pressure: frontal headaches, nausea or vomiting, photophobia, transient visual obscurations, and occasionally progressive visual loss or diplopia $(1,3,15,17)$.

We describe a case of IIH in a 43-year-old woman with schizophrenia treated with risperidone, demonstrating a typical clinical picture of benign intracranial hypertension. In our report, special attention is paid to etiology.

\section{CASE REPORT:}

We demonstrate a case of 43-year old female with schizophrenia diagnosed 10 years ago, and treated with risperidone for 5 years ( $4 \mathrm{mg}$ daily). One month after initiation of treatment with risperidone the patient noted weight gain of $6 \mathrm{~kg}$, and for the 5 years of treatment she put on $35 \mathrm{~kg}$ in total, despite her efforts to keep a strict diet (BMI> 35). Another 3 years later she began to complain of menstrual irregularities and headache. Elevated prolactine level and impaired glucose tolerability were found. The patient has complained of visual obscurations, nausea with vomiting for the last 2-3 months. Neuro-ophthalmologic evaluation showed normal visual acuity of 20/20 (1.0). Ophthalmoscopy revealed bilateral asymmetric papilledema (OD>OS) (Fig.1). Ocular motility, cover test and pupil reaction were normal. Threshold visual field testing shower enlarged blind spots. 
Magnetic resonance imaging was normal. Intracranial pressure was elevated ( $34 \mathrm{~cm} \mathrm{H}_{2} \mathrm{O}$ ); cerebrospinal fluid was normal. IIH was diagnosed. Risperidone was discontinued and replaced with Seroquel $200 \mathrm{mg}$ daily. Treatment with furosemide (Lasix - 2x40 mg) and mannitol 10\% (3x150 ml i.v.) was initiated. The patient was placed on a strict diet again. Papilledema resolved completely over the next 2 months.

The patient was followed-up for four years after risperidone withdrawal. Schizophrenia has been treated successfully with Seroquel $150 \mathrm{mg}$ daily. Weight loss of 28 $\mathrm{kg}$ was noted for four years. There were no relapses of headache, nausea, visual obscuration, menstrual irregularities and hyperprolactinaemia. Ophthalmologic examination revealed no papilledema (Fig.2).

\section{DISCUSSION:}

IIH is a rare disorder, associated with several conditions and risk factors: obesity, weight gain, use of tetracycline antibiotics, vitamin $\mathrm{A}$ and other retinoids $(3,5,7,8,15,17)$. Numerous drugs, including psychotherapeutics, have been associated with IIH, but a causal relationship is only supported by single cases. In some instances visual and neurological disorders in IIH can continue or a relapse may appear despite medication withdrawal. In a small number of patients IIH was associated with lithium use, and in some cases, re-challenge resulted in reappearance of $\mathrm{IIH}(11,13)$.

In our case, a woman with schizophrenia treated for 5 years with risperidone, developed IIH with a typical clinical picture. Soon after initiation of treatment, weight gain was observed, followed by hormonal problems: menstrual irregularities and hyperprolactinaemia. Risperidone can cause sustained hyperprolactinaemia. Weight gain is a well-known adverse effect of risperidone, and at the same time it is associated with greater risk of $\mathrm{IIH}(4,12)$. It could be discussed that in the described case IIH was mainly associated with weight gain, secondary to prolonged use of risperidone, and not with risperidone itself. After Risperidone withdrawal, the four-year follow-up period showed significant weight reduction, normal hormonal state, and no relapses of $\mathrm{IIH}$.

\section{CONCLUSION:}

The association based upon reports of single cases are insufficient to support a causal relationship between risperidone and IIH. More descriptions of similar cases, as well as longer follow-up are needed. However, prolonged use of antipsychotics, such as risperidone, should require proper surveillance for possible development of IIH and routine ophthalmologic examinations should be performed.

Fig. 1. Bilateral asymmetric papilledema $(\mathrm{R}>\mathrm{L})$
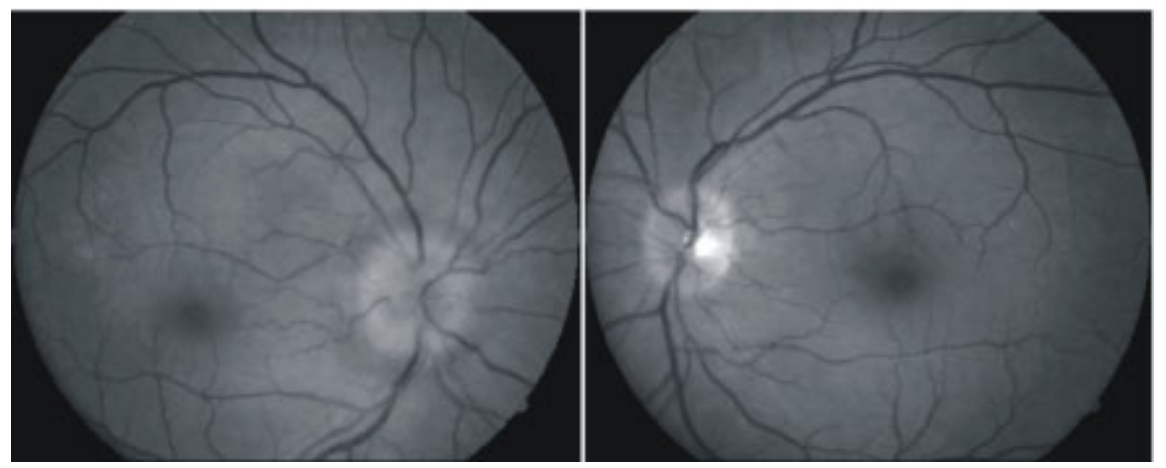

Fig. 2. Ophthalmological examination revealed no papilledema 2 years later.
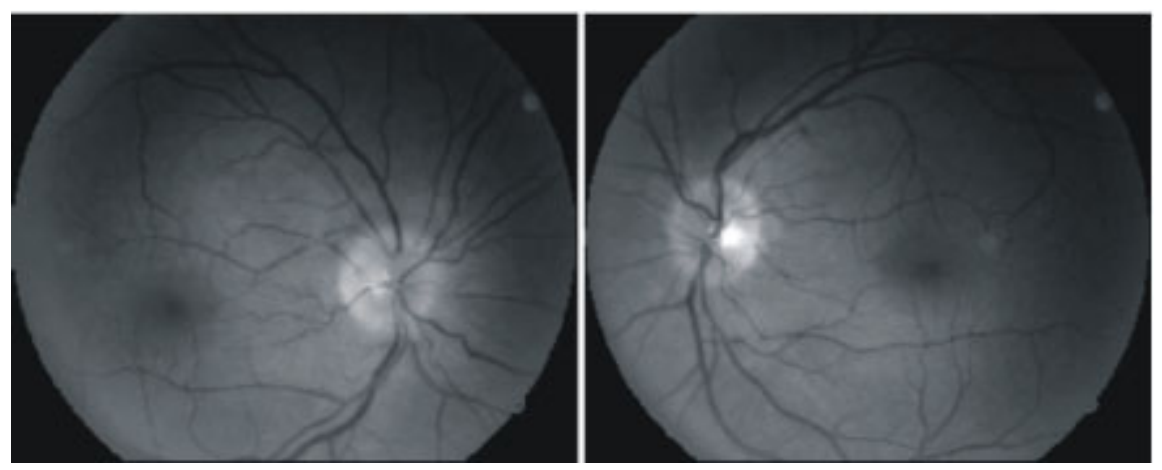


\section{REFERENCES:}

1. Acheson JF. Idiopathic intracranial hypertension and visual function. Br. Med. Bull., 2006; 79-80(1):233-234. Epub 2007 Jan 22. [PubMed] [CrossRef]

2. Akgьn C., Taєkin GA, Akbayram S., Kaya A., Тлтеl H., Yuca SA, Caksen H. A case of idiopathic intracranial hypertension related with vesicoureteral reflux. Hiroshima J Med Sci. 2011 Sep;60(3):67-69. [PubMed]

3. Dhungana S., Sharrack B., Woodroofe N. Idiopathic intracranial hypertension. Acta Neurol Scand. 2010 Feb;121(2):71-82. Epub 2009 Nov 23. [PubMed] [PubMed]

4. Eberhard J, Lindstr E, Holstad M. Levander S. Prolactin level during 5 years of risperidone treatment in patients with psychotic disorders. Acta Psychiatr Scand. 2007 Apr;115(4):268-76. [PubMed] [CrossRef]

5. Errguig L, Benomar A, Aitbenhaddou E, Mouti O, Regragui W, Benaaboud B, et all. Clinical and therapeutic aspects of benign intracranial hypertension. Rev. Neurol. (Paris). 2004 Dec;160(12):1187-1190. (Article in French) [PubMed]

6. Fiebai B., Chukwuka I. Presumed idiopathic intracranial hypertension: A case report and literature review. Niger J Med.
2011 Apr-Jun;20(2):289-291. [PubMed]

7. Friedman D. Papilledema. In: Miller N., Newman N., Biousse V., Kerrison J., eds. Walsh and Hoyt's Clinical neuroophthalmology, $6^{\text {th }}$ ed., Philadelphia, Lippincott Williams \& Wilkins, 2004 (3):237-291.

8. Hannerz J., Ericson K. The relationship between idiopathic intracranial hypertension and obesity. Headache. 2009 Feb;49(2):178-184. [PubMed] [CrossRef]

9. Kesler A., Goldhammer Y., Hadayer A., Pianka P. The outcome of pseudotumor cerebri induced by tetracycline therapy. Acta Neurol. Scand. 2004 Dec;110(6):408-411. [PubMed] [CrossRef]

10. Ko M., Chang S., Ridha M., Ney J., Ali T., Friedman D, et all. Weight gain and recurence in idiopathic intracranial hypertension. Neurology. 2011 May 3; 76(18):1564-1567. [PubMed]

11. Levine SH, Puchalski C. Pseudotumor cerebri associated with lithium therapy in two patients. J. Clin. Psychiatry. 1990 Jun;51(6):251-253. [PubMed]

12. Meyer JM. A retrospective comparison of weight, lipid, and glucose changes between risperidone- and olanzapine-treated inpatients: metabolic outcomes after 1 year. J Clin Psychiatry. 2002 May;63(5):425-433. [PubMed]

13. Saul RF, Hamburger HA, Selhorst JB. Pseudotumor cerebri secondary to lithium carbonate, JAMA, 1985 May 17;253(19):2869-2870. [PubMed]

14. Serratrice J., Granel B., Conrath J., Dufour H., Disdier P., Henry JF, Weiller PJ. Benign intracranial hypertension and thyreostimulin suppression hormonotherapy. Am. J. Ophthalmol. 2002 Dec; 134(6): 910-911. [PubMed]

15. Thambisetty M., Lavin PJ, Newman NJ, Biousse V. Fulminant idiopathic intracranial hypertension. Neurology, 2007 Jan 16;68(3):229-232. [PubMed]

16. Vischi A., Guerriero S., Giancipoli G., Lorusso V., Sborgia G. Delayed onset of pseudotumor cerebri syndrome 7 years after starting human recombinant growth hormone treatment. Eur. J. Ophthalmol. 1, 2006 Jan-Feb;16(1)178-180. [PubMed]

17. Wall M. Idiopathic intracranial hypertension (pseudotumor cerebri). Curr Neurol Neurosci Rep. 2008 Mar;8(2):87-93. [PubMed]

\author{
Address for correspondence: \\ Assoc. Prof. Alexandra Tzoukeva, MD PhD \\ Department of Neurology \\ Prof. Paraskev Stoyanov Medical University of Varna, \\ 55, M. Drinov str., 9002 Varna, Bulgaria \\ E-mail: al_tz@abv.bg;
}

